•保护论坛・

\title{
关于贯彻落实“建立以国家公园为主体的 自然保护地体系”的六项建议
}

\author{
杨 锐 $^{{ }^{*}}$ 申小莉 ${ }^{2}$ 马克平 ${ }^{2}$ \\ 1 (清华大学国家公园研究院, 北京 100084) \\ 2 (中国科学院植物研究所植被与环境变化国家重点实验室, 北京 100093)
}

\section{Recommendations on building up China's National-park-centric Protected Area System}

\author{
Rui Yang ${ }^{1 *}$, Xiaoli Shen ${ }^{2}$, Keping Ma ${ }^{2}$ \\ 1 The National Park Institute, Tsinghua University, Beijing 100084 \\ 2 State Key Laboratory of Vegetation and Environmental Change, Institute of Botany, Chinese Academy of Sciences, \\ Beijing 100093
}

自2013年11月十八届三中全会提出“建立国家 公园体制”以来，中国在不到5年时间中，以国家公 园体制建设为契机，在全面深化自然保护地体制 改革方面取得了里程碑式的重大进展, 为实现生 态文明和美丽中国国家战略奠定了坚实基础。为了 更好地贯彻落实十九大报告提出的“建立以国家公 园为主体的自然保护地体系”, 我们提出以下六项 建议:

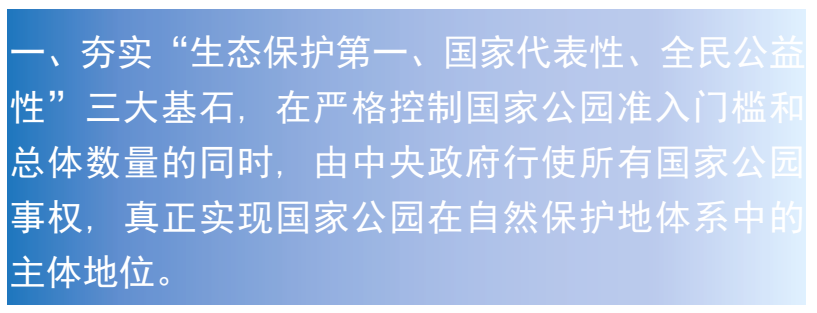

“生态保护第一、国家代表性、全民公益性”是 生态文明新时代对中国国家公园体制建设的总体 要求, 是中国国家公园建设的鲜明特征, 因此夯实 这三块中国国家公园体制建设的基石是第一要务。 为此, 建议中国国家公园定位为“由中央政府批准 设立并行使事权, 边界清晰, 以保护具有国家代表 性、原真性和完整性的大面积生态系统和大尺度生
态过程为主要目的, 实现科学意义上最严格保护的 特定陆地或海洋区域”。这个定位中强调了由中央 政府行使所有国家公园的事权, 而不是部分国家公 园由中央委托省级人民政府行使事权。这是因为, 分级事权与国家公园的重要地位不符, 也不利于 “生态保护第一、国家代表性、全民公益性”三大理 念的真正实现。美国约塞米蒂国家公园建园初期的 历史就是一个可供借鉴的失败案例。

建议依据生态系统和生态过程特征, 将国家全 部陆地和海洋划分为不同的生物地理单元, 在每一 单元内选择最具代表性、原真性和完整性的区域作 为国家公园潜在建设地区, 列入国家公园预备名录。 为了实现所有国家公园由“中央政府行使事权”和“科 学意义上最严格保护”, 建议中央政府严格控制国家 公园准入门槛和数量。由中央政府组织多学科专家 根据原真性、完整性和适宜性的要求, 制定中国国家 公园发展规划; 并根据每一个国家公园的特征、管理 目标和现状制定该国家公园管理实施细则。

以这种最高标准和最严格程序建立起来的国 家公园将成为美丽中国的璀㻧明珠，成为生态文明 新时代中国自然保护地的杰出代表和保护管理典

* 通讯作者 Author for correspondence. E-mail: yrui@mail.tsinghua.edu.cn 
范，因此也最能体现国家公园在自然保护地体系中 的主体地位。

\section{根据保护对象特征和保护强度差异} 合理的自然保护地体系，建立金字塔型 公园为主体的自然保护地体系”法律框架 分别制定针对不同类型自然保护地差异化 策。

中国的自然保护地目前占国土面积的18\%, 今 后还有可能进一步增长。不同个体自然保护地其资 源特征各不相同(山水林海湖草沙); 保护对象各有 区别(生态系统、生态过程、物种多样性、文化景观 等); 占地规模大小不等(从几百平方公里到十几万 平方公里); 土地权属复杂多样(国有土地、集体土 地叠加承包确权); 财政事权也不尽相同。因此, 如 此大规模的自然保护地不可能采取简单、粗放、“一 刀切”的管理政策, 而应根据保护对象的特征, 构 建系统合理的自然保护地体系, 并分别制定不同类 型自然保护地管理政策, 进行差异化、精细化、科 学化管理。

法律框架是自然保护地持续发展的根本保障。 建议中国“以国家公园为主体的自然保护地体系”法 律框架由 “ $1+\mathrm{N}+\mathrm{X}$ ”三层金字塔结构组成。位于最顶 层的“ 1 ” 是指《自然保护地法》, 它是整个法律框架 的根基; 中间层“ $\mathrm{N}$ ”指 $\mathrm{N}$ 项国务院条例，有几类自然 保护地就设置几个条例, 例如: 《国家公园管理条 例》、《自然保护区管理条例》(由现有自然保护区条 例修订形成)、《自然栖息地管理条例》、《风景名胜 区管理条例》(由现有风景名胜区条例修订形成)等 等; 最底层的“ $X$ ” 是指根据《国家公园管理条例》, 按照“一园一法”为每个个体国家公园制定的管理实 施细则, 例如《祁连山国家公园管理实施细则》等。

建议根据保护管理强度和目标制定国家公园 功能分区。可分为核心保护区、生态保育区和限制 利用区三种类型。核心保护区严格禁止人工设施建 设和人类活动干扰; 生态保育区仅允许科研活动和 栖息地管理等生态保育措施; 限制利用区严格限制 非保护管理需要的人工设施建设, 可进一步分为传 统利用区和科普游咊区, 需科学制定社区人口和环 境教育的承载量。
、借鉴国际荒野保护的先进理念、政策和拉 法管理自然保护地核心区; 建立中国荒野保 度, 抢救性保护原真性最高的国家自然遗产

中国自然保护地原真性和生态价值最高的部 分是国家公园和自然保护区的核心区。最有必要进 行“最严格的保护”，且“最严格保护”可行性最高的 部分，也是自然保护地的核心区。从某种意义上讲, 核心区保护管理的质量决定了中国自然保护地的 保护管理质量。核心区如何保护管理是“建立以国 家公园为主体的自然保护地体系”中的关键和核心 任务之一。

建议中国自然保护地的核心区，尤其是国家公 园和自然保护区的核心区，比照国际荒野保护的先 进理念、政策和技术方法进行管理。荒野是原真性 最高，人类干扰强度最低，也基本没有人类聚居的 自然区域。荒野保护区位于IUCN自然保护地分类 的第一层次, 其保护目标、力度和强度最接近我国 国家公园和自然保护区的核心区。

荒野不是某一种类型的自然保护地，不具有 行政地位，而是各类自然保护地中实行“最严格保 护”的管理政策单元。目前国家公园体制试点中, 大多在边界范围内都有数以万计的人口居住生活, 因此在较长一段时间内, 不可能实行全域范围的 “最严格保护”。建议在国家公园等自然保护地内以 尽可能大的面积划定荒野保护区域，建立中国荒 野保护制度，抢救性保护原真性最高的国家自然 遗产。

\section{四、充分重视土地权属的复杂性和社区管理白 \\ 性，根据不同地区国家公园建设中土地、 区的特征、问题、困难及其根源制定专项管理政 预防 “一刀切” 政策可能带来的长期隐曾}

中国国家公园体制建设中最具挑战性的问题 是土地和社区人口。拟建国家公园地区土地权属 的复杂程度在世界上都是罕见的。同时，大多数拟 建国家公园和自然保护地内外居住生活着大量农 牧民、林业职工甚至城市居民。土地、人口和社 区三者的特征、问题、困难及其根源如果没有得 
到深入调研，并在此基础上针对不同地域、不同情 境提出实事求是并富有创造性的一揽子解决方案, 中国的国家公园和自然保护地发展将存在长期 隐患。

建议组织多学科专家对土地、社区和人口问题 进行专题调研和专项研究, 尤其要研究国家公园内 土地所有权、管理权和使用权现状, 土地确权对国 家公园管理的影响，实行地役权、保护权、协议共 管等社区参与国家公园保护和管理制度的可行性, 并在此基础上由国家公园主管部门分别制定国家 公园土地管理专项政策, 以及社区和人口管理专项 政策。

\section{五、充分发挥科学研究和科学家群体在国家公 设中的独特作用, 以科学为准绳实现 保护”。}

“科学”是国家公园体制建设中不可或缺的要素 之一, 也是目前中国各种类型自然保护地的短板。 作为自然保护地体系的主体, 国家公园应该在科学 立法、科学规划、科学保护、科学管理、科学监测 方面做出示范, 实现国家公园以科学为准绳的“最 严格的保护”。

建议成立“中国国家公园科学指导委员会”, 聘 任有理想、有操守、有能力、有思路的多学科专家, 承担国家公园建设方面的顶层科学咨询工作; 施行 国家公园首席科学家制度, 由国家公园主管部门为 每一个国家公园指定首席科学家; 建立生态保护科 学部门, 负责该国家公园的规划、保护、管理和监 测工作；尽快依托“双一流”大学或学科来建设“国 家公园人才培养基地”, 协调教育主管部门落实研 究生名额, 用以培养国家公园高层次人才。

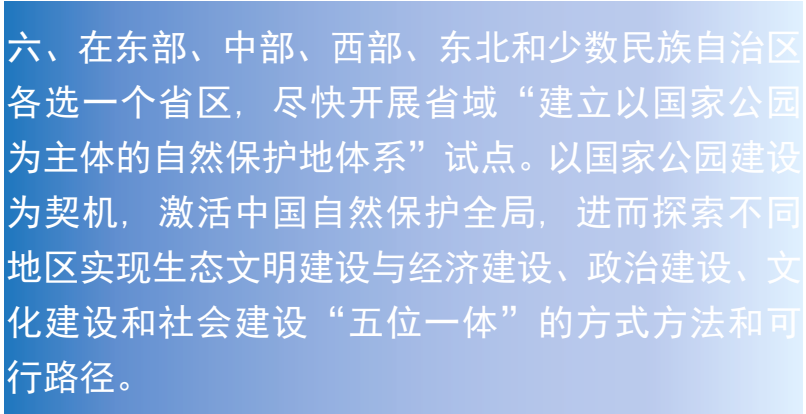

与“建设国家公园体制”相比, “建立以国家公园 为主体的自然保护地体系” 是一项更为宏大、艰巨、 复杂的任务。不仅影响中国自然生态保护的全局, 而且还与脱贫攻坚、城镇和人口布局、产业转型、 民族稳定、国防安全、生态红线、主体功能区等有 着千丝万缕的联系。兹事体大, 实施过程中一定不 能草率落实。建议在现有国家公园体制试点基础上, 总结经验教训, 尽快开展“建立以国家公园为主体 的自然保护地体系”省级试点。

中国地域辽阔，人口众多，生态环境丰富多 样。在“建立以国家公园为主体的自然保护地体系” 的过程中，东部、中部、西部和东北地区分别面临 着不同的挑战和矛盾，尤其是不同的土地和社区人 口管理问题。建议综合考虑地域特点、保护对象差 异、经济发展水平、民族人口构成等因素，在东部、 中部、西部、东北和少数民族自治区各选一个省区， 尽快启动省域“建立以国家公园为主体的自然保护 地体系”试点工作，以国家公园建设为契机，探索 不同地区实现生态文明建设与经济建设、政治建 设、文化建设、社会建设“五位一体”的方式方法和 可行路径。

致谢: 本项研究得到中国环境与发展国际合作委员 会“2020后全球生物多样性保护专题研究”的支持, 初 稿完成于2018年7月13日。其后与Arthur Hanson、李 琳、高吉喜、Harvey Locke等国内外专家进行了若千 轮讨论, 吸收了他们的宝贵意见和建议, 特此致谢。 